\title{
The Phantom Menace: Novel Psychoactive Substances and the UK Armed Forces
}

\section{Key Points}

- Novel psychoactive substances (NPS) are compounds synthesised to mimic the effects of recreational drugs

- $\quad$ Research in the UK and the USA suggests that the use of NPS is becoming more prevalent amongst Armed Forces Personnel

- $\quad$ Civilian population data suggest that young males (16-24) are most likely to misuse NPS

- There is no unifying NPS toxidrome; identification of the subtype of NPS will greatly assist the military clinician in targeting supportive treatment

- $\quad$ NPS misuse may result in long term psychiatric and physical ill health; hence their use is entirely incompatible with Service Life

\section{Introduction}

Novel psychoactive substances (NPS) encompass a large group of synthesised compounds specifically designed to mimic traditional recreational drugs. Current UK Armed Forces compulsory drug testing (CDT) does not screen for these substances, making them tempting to the small proportion of UK Armed Forces personnel who indulge in recreational drug use. The acute and chronic sequelae of NPS misuse are widely variable, and associated with high morbidity. In this paper, we discuss NPS pharmacology and clinical presentation. We recommend a standard management plan for the Military Physician encountering a service person who has misused NPS. Finally, we reflect on the legal, ethical and military consequences of NPS misuse for both the service person misusing NPS, and the Military Physician providing their care.

\section{What are Novel Psychoactive Substances (NPS) and who uses them?}

Novel psychoactive substances (NPS), better known as "designer drugs" (or colloquially as "legal highs"), are substances produced to mimic the effects of taking a traditional illegal recreational drug (1). They can be broadly categorised by effect as synthetic cannabinoids, stimulant type drugs (notably synthetic cathinones), hallucinogenic type drugs, opioid type drugs and tranquiliser type drugs, and are traded under a variety of street names and descriptors (2). Until the enactment of the May 2016 Psychoactive Substances Act, NPS were readily available for legal purchase on high streets in "head shops" and over the Internet (3); hence the 
misnomer "legal highs". Despite the 2016 ban, NPS remain available, illegally, on the Internet and via illicit drug dealers (4).

It is difficult to quantify NPS use. A European survey of $>13000$ young adults (those aged 15 to 24 ) in 2014 indicated that $8 \%$ had tried NPS (1). Another source, surveying young adults (aged 16 to 24 ) in England and Wales in 2014 , estimates around 360,000 of this cohort had tried NPS in their lifetime, while 174,000 had used NPS in the last year(2). Accurate data on use of NPS within the UK is difficult to capture due to poor response rates from those surveyed, and the nebulous nature of NPS themselves. These are frequently rebranded and may contain a mixture of substances unbeknownst to the self-reporting user $(1,3,5,6)$. The Home Office review of NPS use and social impact notes that the majority of those taking NPS are already using illicit drugs (1).

Novel psychoactive substances use in the UK Armed Forces is even more difficult to define. Armed Forces personnel are subject to randomised compulsory drug testing, which tests urine for "traditional" drugs of abuse as defined in the Misuse of Drugs Act 1971 (e.g. cocaine, heroin, ecstasy, anabolic steroids and lysergic acid diethylamide (LSD)) A freedom of information request to the Ministry of Defence (MoD) for the period October 2015-2016 reported that 660 UK Armed Forces personnel tested positive for illicit drugs on CDT. During that time period, both "traditional" recreational drugs and NPS were recovered from UK Military bases, including Metandienone, and Mephedrone(7). In 2007, one report noted that the cost to the British Army of drug related discharges was more than the number of personnel killed on active duty and more than the number killed in the Iraq and Afghanistan wars (8).

Currently, the UK Armed Forces CDT does not include NPS, and until recently, no tests were available (9). Joint Service Publication (JSP) 835 clearly states that drugs of abuse, including NPS, are not tolerated within the UK Armed Forces. Use of NPS by personnel will almost always result in administrative or disciplinary action, including discharge from the Armed Forces (though single Services may choose to retain personnel under exceptional circumstances)(9) Disciplinary action would relate to unfitness to work or misconduct through the use of drugs (10). It is easy to imagine that the small number of personnel inclined to misuse drugs would choose to avoid detection by using NPSs. 
The Home Office have identified compulsory drug testing as a motivating factor for NPS use (1). One expert hypothesises that a reduction in UK Armed Forces personnel testing positive for cocaine in 2009 was due to this cohort switching to the then legal drug mephedrone (11). A similar displacement was hypothesised when compulsory drug tests (CDT) were first introduced in to the UK Armed Forces (and UK Prisons (12)). The introduction of CDTs with punitive sanctions saw soldiers switch from Class B drugs, like cannabis, to Class A drugs (such as cocaine) that could be eliminated from their system in a shorter period of time, thus circumventing a positive CDT (8).

While there is little data pertaining to the use of NPS among UK Armed Forces personnel, there is evidence to suggest NPS use is prevalent in the United States military; a comparable cohort. A number of high profile cases show synthetic cannabinoid, and to a lesser extent synthetic cathinone use is prevalent across the US Army, Air Force and Navy (13-15) in all ranks (16). One paper reports $>100$ discharges from the US military for NPS use between June 2011 and January 2012(17), whilst another reported that in 2012, 2.5\% of 10,000 US Army drug tests that had initially registered as negative flagged as positive when tested for synthetic cannabinoids (18). These findings neatly illustrate how the use of NPS avoids a positive CDT, and may lead to under-reporting for NPS use.

A study examining hospital admissions of US service personnel due to substance misuse, found that $8.3 \%$ (13 of 155) had used "Bath Salts" (a stimulant type drug) and 7.7\% (12 of 155) had used "Spice" (a synthetic Cannabinoid). The majority of patients in this study were male and aged under 30 (11). According to the Home Office young males aged between 16-24 were not only significantly more likely (three times more likely) than females to take NPS (2). Ministry of Defence biannual diversity statistics for October 2016 indicate that young male recruits make up 22.28\% of the UK regular Armed Forces (33, 470 males aged 16-24) (19). Military physicians in primary and acute care should be aware of the potential for NPS misuse within the UK Armed Forces population, particularly among the young, male recruits.

\section{Acute presentation of NPS}

The presentation of NPS in the primary or acute care setting may be far more varied than the presentation of "traditional" drugs of misuse. This is due, in part, to the variation in chemical content of NPS (even when 
branded identically)(4), and also the relative strength of these compounds compared to "traditional" drugs (20). Table 1 illustrates the pharmacology of the four categories of NPS discussed in this paper. Table 2 illustrates the subtypes of NPS, their street names, and systemic effects. 


\begin{tabular}{|c|c|c|c|c|}
\hline NPS Subtype & Receptor & $\begin{array}{l}\text { Methods of } \\
\text { Administration }\end{array}$ & Time to onset of High & Length Of “High” \\
\hline SYNTHETIC CANNABINOIDS & $\begin{array}{l}\text { CB1 receptor in Brain, GI tract, } \\
\text { Lungs, Kidney } \\
\text { CB2 receptors in Brain (14) }\end{array}$ & Smoking & $\sim 10$ mins & 2-6 hours (16) \\
\hline STIMULANT TYPE DRUGS & $\begin{array}{l}\uparrow \mathrm{DA}, 5 \mathrm{HT} \text {, NA within the synapse } \\
\text { Inhibits MAO ( } \downarrow \text { DA, } 5 \mathrm{HT}, \mathrm{NA} \\
\text { reuptake within synapse) (21) }\end{array}$ & Intranasal, Intravenous & $30-90$ mins & $2-8$ hours $(17,26-28)$ \\
\hline $\begin{array}{l}\text { HALLUCINOGEN TYPE DRUGS } \\
\text { - PHENYETHYLAMINES (inc. 2C series) } \\
\text { - BROMO-DRAGONFLY }\end{array}$ & $\begin{array}{l}\text { Partial agonists at } 5 \mathrm{HT} 2 \mathrm{~A} \text { serotonin } \\
\text { receptor }(22-23) \\
\text { Full agonist at } 5 \mathrm{HT} 1,5 \mathrm{HT} 2 \& \alpha 1 \\
\text { adrenergic receptors }(24-26)\end{array}$ & $\begin{array}{l}\text { Orally, sublingually (from } \\
\text { blotting paper), intranasal, } \\
\text { intramuscular, } \\
\text { intravenous, per vaginum, } \\
\text { per rectum, smoked. }\end{array}$ & $\begin{array}{l}0-15 \text { mins } \\
\geq \text { 6hrs (high risk redosing) }\end{array}$ & $\begin{array}{l}15-90 \text { mins (22) } \\
\text { Several days (29) }\end{array}$ \\
\hline - METHOXETAMINE & $\begin{array}{l}\downarrow D A \text { reuptake } \\
\text { NMDA glutamate receptor } \\
\text { antagonist } \\
\text { Agonist at muscarinic cholinergic } \\
\text { and } 5 \mathrm{HT} 2 \text { receptors }(30-31)\end{array}$ & & $\sim 10$ mins & 2.5-5hrs (31) \\
\hline OPIOID TYPE DRUGS & Agonists at $\mu \& \mathrm{k}$ opioid receptors & $\begin{array}{l}\text { Oral, subcutaneous } \\
\text { injection, intravenous }\end{array}$ & Agent dependent & Agent dependent \\
\hline TRANQUILIZER TYPE DRUGS & Agonists at the $G A B A_{A}$ receptor & $\begin{array}{l}\text { Orally, sublingually (from } \\
\text { blotting paper), } \\
\text { intravenous, transdermal } \\
\text { patches, spray (33-35) }\end{array}$ & $\begin{array}{l}\text { Agent dependent } \\
\text { Phenazepam } 4-6 \mathrm{hrs} \\
\text { Etizolam } 30 \text { mins-2hrs } \\
\text { Pyrazolam } 1-1.5 \mathrm{hrs}\end{array}$ & $\begin{array}{l}\text { Agent dependent } \\
\sim 8 \mathrm{hrs} \\
15-60 \mathrm{hrs} \\
16-18 \mathrm{hrs}\end{array}$ \\
\hline
\end{tabular}

Key: $\mathrm{CB}=$ Cannabinoid receptor, $\mathrm{DA}=$ Dopamine, $5 \mathrm{HT}=$ Seratonin, $\mathrm{NA}=$ Noradrenaline, $\mathrm{MAO}=$ Monoamine Oxidase, NMDA = N-Methyl-D-aspartate, GABA $=$ gamma-Aminobutyric acid

Table 1: Pharmacology and pharmacokinetics of the subtypes of Novel Psychoactive Substances 


\begin{tabular}{ll} 
Drug Class & Street names* \\
\hline \multirow{2}{*}{ Synthetic Cannabinoids } & Spice, K2, Black Mamba, \\
& Clockwork Orange, \\
& Ecstacy Damnation, \\
& Psyclone, Sensate, \\
& Abyss, Magic Dragon, \\
& K92 Genie, Yacatan Fire \\
& $(2,9,35,36)$ \\
Stimulant type drugs & Bath salts, BZP, meph, \\
(Synthetic Cathinones, & m-cat, MCAT, Miaow, \\
Piperazines and & miaew, 4-mmc, bubbles, \\
Mephedrone) & white magic, plant \\
& feeder, NRG-1, Benzo \\
& Fury, MDAI, Bloom, \\
& Ivory Wave, Charge+, \\
& Sextacy (2, 17, 42)
\end{tabular}

Hallucinogen type drugs (Phenylethylamines, Bromo Dragonfly and Methoxetamine) -Dragonfly, 2C-B, BOMe2CC, Boom, CBoom, Cimbi-82, Special K, Mexxy, M-ket, MEX Kmax, Special M, MA, legal ketamine, Minx, Jipper, Roflcoptr $(2,3,5$, 22 27)

AH-7921, Doxylam, W Euphoria, $157, W 18, W 19(2,45-$ 46)

Tranquiliser type drugs Xany, Etizolam, Relaxation (47-53)
Desired effect

Euphoria, relaxation, disinhibition, altered consciousness (2)

CNS

Anxiety/panic, psychosis, short term memory

impairment, seizures,

hallucination, movement

disorders, self-mutilation,

suicidal ideation $(2,2035$,

36-37)

Euphoria, sexual Confusion, agitation, stimulation,

empathy,

increased work

capacity $(2,21)$

seizures, psychosis,

paranoia, panic, muscle

spasms, vertigo, tinnitus,

short term memory

impairment,

parkinsonism, motor

automatisms, cerebral

oedema, violent

behaviour, depression

suicidal ideation,

dependency 2, 23 - 26

Confusion, self-

Hallucinations,

sense of peace,

harming/bizarre

behaviour, agitation

acute and delayed

stimulation,

amphetamine-like seizures, increased

stimulation,

muscle tone, clonus,

headache, flashbacks,

paranoia, cerebellar

ataxia $(22-26,309)$

Nightmares, anxiety,

agitation, dysphoria

depression, paranoia (46)

Drowziness, hypotonia,

in-coordination, ataxia,

dysarthria, nystagmus,

coma (47-53)
Tachycardia, hypertension, chest pain, ischaemia

(including troponin $+v e$

STEMI), dysrhythmias

$(35,38-39)$

Tachycardia,

hypertension, chest

pain, S-T ECG changes,

dysrhythmias,

myocardial infarction,

myocarditis, syncope

$(2,21,27,42)$

Tachy or bradycardia,

hyper/hypotension,

dysrhythmias, heart

murmurs, coronary

vasospasm, heart

failure.

Bromo Dragonfly:

vasoconstriction (+)-

irreversible peripheral

ischaemia) (2, 22-36,

Possible cardiotoxicity;

Prolonged QT, widened

QRS (46)

\section{Hypotension,}

bradycardia (47-53)

Nausea,

vomiting,

diarrhoea,

stomach

lining

irritation (22

$26,30)$

Nausea,

Vomiting (46) rhabdomyolysis post injection (46)

Hypothermia,

rhabdomyolysis (47-52)

\section{Other}

Nystagmus, xerostomia mydriasis, conjunctival

hyperaemia $(35,41)$

kidney injury,

yperglycaemia, other

$(27,35,41)$

Hyperthermia,

yponatraemia,

hypokalaemia, acidosis,

acute kidney injury,

Syndrome $(2,21,27,42)$

Hyperthermia, metabolic acidosis, acute kidney

injury, rhabdomyolysis,

Syatonin Syndrome,

dysuria $(230,43-44)$
Hepatic failure,

disseminated

intervascular coagulation

injection site injuries

(including necrotising

fasciitis), rash,

compartment syndrome, spontaneous

subcutaneous

emphysema, abscesses,

body odour $(2,21,27,42)$

Pulmonary oedema,

respiratory depression

hepatic impairment,

mydriasis, disseminated

intravascular coagulation

diaphoresis, bruxism 130

43)

\section{Respiratory depression}

pulmonary oedema,

injection site soft tissue

infections, miosis (46)

Respiratory depression

(47-53)

Key: CNS = Central Nervous System, CVS = Cardiovascular System, GS = Gastrointestinal System

Table 2: Illustrating categories of NPS, some street names, and how they present in the acute setting 


\section{Synthetic Cannabinoids}

Synthetic cannabinoids are manufactured chemicals that are sprayed on to plant matter and consumed in a similar way to marijuana (most commonly smoking). However, whilst the consumption of marijuana has relatively predictable results (euphoria, relaxation, hunger), synthetic cannabinoids are often more potent, and present in a more variable manner (54) (see Table 2). Case studies report that in addition to the "desirable" effects of euphoria and altered consciousness, substance users may experience psychological effects ranging from anxiety and memory loss to violent psychosis $(2,20,35)$. In some cases, psychosis has persisted for months after the initial ingestion of the synthetic cannabinoid, requiring treatments with antipsychotic medication and hospitalisation (55). Research suggests that the risk for psychosis increases for individuals with a history of mental illness (56). Recent MoD statistics suggest the rate of mental disorders among UK Armed Forces personnel is higher than the UK general population at $2.9 \%$ (57). Hence, it may be argued that Armed Forces personnel who misuse synthetic cannabinoids may be at greater risk of developing psychosis.

Cardiovascular side effects are commonly reported, and range from tachy/bradycardias and hypertension, to chest pain, dysrhythmias, ischaemia, and troponin positive ST segment elevation myocardial infarction (35, 3940). One case series reports three 16 year olds who presented with myocardial infarction after smoking the synthetic cannabinoid K2. All three had structurally normal hearts (40).

Gastrointestinal effects of synthetic cannabinoids include nausea, vomiting and hyperemesis $(2,14,36,38)$. "Cannabinoid hyperemesis syndrome" is a cycle of nausea, abdominal pain, and vomiting normally associated with heavy marijuana use. Recently, cannabinoid hyperemesis syndrome has also been associated with the misuse of synthetic cannabinoids (39). In two cases reported, nausea and vomiting were the initial symptoms in a Spice induced fatal rhabdomyolysis. Both young male patients died within a week of synthetic cannabinoid ingestion, despite critical care interventions (41). Acute kidney injury has also been linked to the ingestion of synthetic cannabinoids (58). This deleterious effect on the kidneys may also contribute to the electrolyte and acid base disturbances which have been observed in synthetic cannabinoid users $(35,41,58)$.

Whilst relatively few papers report deaths from ingestion of synthetic cannabinoids or their sequelae, they may cause considerable physical and psychiatric morbidity in those taking them $(36,58-61)$. The symptoms 
arising from synthetic cannabinoid use may have serious implications for Armed Forces Personnel and their immediate and long term fitness for duty. As illustrated in Table 2, there is no obvious toxidrome indicating synthetic cannabinoid intoxication. The CDT does not identify synthetic cannabinoids or their metabolites, and formal toxicology screening may be of little use, particularly if the synthetic cannabinoid is a new compound (59, 61-62). Treatment is largely supportive (fluids for acute kidney injury, antipsychotics for psychosis)(59, 62). In Figure 1, we suggest an approach to the assessment and management of UK Armed Forces personnel who may be intoxicated with NPS.

\section{Figure 1}

\section{Stimulant Type Drugs}

Stimulant type drugs, including synthetic cathinones such as mephedrone, are often marketed as "bath salts" or "plant food" $(17,28,42)$. Cathinones are naturally found in the leaves of the African khat plant, and chewed as a stimulant in some cultures (2). Mephedrone (4-methyl- $N$-methylcathinone) deserves an individual mention, as it has been linked to a significant number of fatalities. One study reports 30 deaths related to mephedrone in people aged 16-24 in the UK over a 4 year period (28). Another paper reports 62 mephedrone associated deaths in the UK over 2 years, attributed to both acute toxicity and fatal self harm under the influence of the drug (27).

Unlike traditional stimulant drugs (e.g. cocaine), synthetic cathinones have qualities mimicking ecstacy and amphetamines, causing euphoria, sexual stimulation, empathy, increased alertness and capacity for work, and hallucinations $(2,17,28)$. The pharmacokinetic and clinical characteristics of these substances are illustrated in Tables 1 \& 2.

The neurological and psychiatric sequelae of using synthetic cathinones are varied, and range from motor dysfunction to severe psychosis. Cathinone toxicity has been associated with extreme behaviours, often referred to as excited delirium syndrome. This causes a hyperdopaminergic state linked to violent behaviour, agitation, and can lead to self-mutilation, homicidal activity and sudden death (63-65), . Fatalistic self-harm caused by depression or psychosis is one of the main causes of death among cathinone users (64-66). US military data, implicating synthetic cathinone use in both suicide and murder-suicide, is of particular interest $(14,42)$. This is particularly relevant to UK Armed Forces populations, as, unlike most UK citizens, they have relatively easy access to weapons systems (such as rifles and hand guns). 
Due to their stimulation of the sympathetic nervous system, the cardiovascular effects of synthetic cathinones may be readily anticipated. Tachycardia and hypertension are common, as is chest pain and ST segment changes (which may be rate related or due to coronary vasospasm in a younger cohort). Narrow complex tachycardias, ventricular tachycardia (VT), ventricular fibrillation (VF) and myocardial infarction are also reported $(21,42,67)$. Two case reports discuss asystolic cardiac arrest as a result of ingesting synthetic cathinones; in both cases, the subjects were young ( 28 and 44 years of age) and male. One died following 30 minutes of resuscitation effort and was found to have pulmonary oedema. The other was successfully resuscitated but died on intensive care $24 \mathrm{hrs} \mathrm{later,} \mathrm{as} \mathrm{a} \mathrm{result} \mathrm{of} \mathrm{cerebral} \mathrm{and} \mathrm{pulmonary} \mathrm{oedema} \mathrm{(68-69).}$

Gastrointestinal effects of synthetic cathinones are non-specific; and may not be as diagnostically helpful as the metabolic and renal sequelae of synthetic cathinone abuse. Hyperthermia is a widely reported side effect of synthetic cathinone abuse; both as an individual sign and as part of the serotonin syndrome. Temperatures $\geq 41.5^{\circ} \mathrm{C}$ have been recorded $(21,27)$. In severe cases, rhabdomyolysis, acute kidney injury, lactic acidosis and deranged electrolytes are reported; of note, hypokalaemia and hyponatraemia, which undoubtedly contribute to cerebral oedema. Individuals thus compromised invariably need critical care intervention, and may require renal replacement therapy $(2,17,27,68)$. Synthetic cathinones have the potential to create a metabolic "perfect storm", affecting multiple organs in an unpredictable manner and requiring intensive medical intervention in order to avoid death.

Mainstays of treatment for synthetic cathinone toxicity include benzodiazepines and antipsychotics, which is symptomatic and focuses on reducing sympathetic overstimulation $(64,70)$. Currently, no antidote exists to counteract synthetic cathinone toxicity (71). Continued abstinence from the drug is vital. For those who develop single or multi-organ failure, early intervention with critical care input is key, including aggressive cooling and electrolyte replacement $(25,29,42)$.

Longer term sequelae of synthetic cathinone abuse are difficult to predict. Case studies report that regular users of synthetic cathinones may exhibit psychiatric symptoms for weeks to months post ingestion $(27,29)$. Physical ill health is again difficult to predict; however, it can be hypothesised that those misusing synthetic 
cathinones could face chronic cardiac or renal impairment. Such behaviours and sequelae are incompatible with a career in the UK Armed Forces.

\section{Hallucinogen type drugs}

The hallucinogen type NPS may be considered as three subcategories due to their differing pharmacology, described in Table 1. All of these NPSs are ingested for their hallucinogenic and emotionally stimulating properties; however, their distinctive pharmacology determines the severity and potential lethality of their sequelae.

Adverse effects of the hallucinogen type drugs are shown in Table 2. Neuro-psychiatric side effects are common, and seizures may follow ingestion of all three drugs. Bromo dragonfly has been reported to cause delayed onset seizures taking place $>8 \mathrm{hrs}$ post ingestion $(23-26,30-31,43,45,72)$.

Gee et al report on a case series of 10 patients who took 2C series phenylethylamines; common findings were hypertension (8/10) and tachycardia (10/10; ranging from 100 to $175 \mathrm{bpm}$ ) (23). Due to their action at the 5HT2A serotonin receptor, coronary vasospasm and peripheral vasoconstriction would be anticipated. These have been reported, but the degree to which they affect the vasculature is highly variable (due to the partial agonism at 5HT2A receptors), and depends on the dose and chemical taken $(22,72)$. In contrast, Bromo Dragonfly's potent action at the 5HT1 and 2 receptors and the $\alpha 1$ adrenoceptor greatly increase the risk of vasospasm, and peripheral vasoconstriction resistant to vasodilators has been reported, leading to gangrene and amputation of extremities. It is hypothesised that vasospasm following Bromo Dragonfly ingestion contributes to acute kidney injury and ischaemic hepatitis in these patients $(25-26,45)$. Methoxetamine users may also present with hypertension and tachycardia. ST segment elevation myocardial ischaemia (in a 21 year old male) is reported (44).

All of the hallucinogenic NPS compounds may induce gastrointestinal upset in the form of nausea, vomiting or diarrhoea $(22-26,29-30)$. As illustrated in Table 2, the serotonergic effects of all three drugs may induce hyperthermia (reported frequently), Serotonin syndrome, and subsequently rhabdomyolysis, acute kidney injury (potentially requiring renal replacement therapy) and metabolic acidosis $(30,43-45)$. Interestingly, 
methoxetamine is often marketed to ketamine misusers as "bladder friendly" (i.e. lacking the lower urinary tract symptoms that ketamine will typically cause.) Animal studies indicate that this is not the case, and methoxamine may be just as irritating to the urinary tract as ketamine (71).

\section{Opioid type drugs}

There is little information surrounding the misuse of synthetic opioids, although the effects of taking them are somewhat more familiar to the clinician (Table 2). As with "conventional" opioids such as heroin or morphine, those taking these drugs may experience nightmares, agitation, paranoia, anxiety and depression. There is potential for them to cause cardiotoxicity in the form of QT prolongation or widening of the QRS (see Figure 2). If opioid type drugs are injected, injection site soft tissue infections, abscesses or rhabdomyolysis may occur (46). However, the key danger of opioid type NPS is their potency. The "W series" of synthetic opioids are pure $\mu$-agonists, with $\mathrm{W}-18$ being the most potent. They all have the potential to cause rapid respiratory depression and death (45). Miosis and respiratory depression may give the clinician a clue to the substance taken, but toxicologists predict that extremely high doses of naloxone would be needed to reverse the effects of these drugs $(45,46)$. In the age of online shopping, the Military Physician should consider the source of opioid in service personnel presenting in this manner, and be aware of the potent opioid analogues available for purchase on the internet.

\section{Tranquiliser type drugs}

The tranquiliser type drugs used as recreational substances are benzodiazepines without license in the UK (such as etizolam and phenazepam), and benzodiazepine analogues created for research purposes or specifically for the NPS black market (such as pyrazolam). These NPS are taken recreationally for their relaxing and anxiolytic properties. They act at the GABA benzodiazepine receptor, and vary widely in their potency, onset of action and half-life.

The tranquiliser type NPS are taken as standalone recreational drugs, but are also used in combination with other "traditional" drugs and/or NPS. A proportion of recreational substances marketed as "traditional" drugs or NPS have been found to be contaminated with tranquiliser type drugs $(51,52)$ and NPS have been found in products marketed and sold as benzodiazepine replacements (74). Due to their benzodiazepine like properties, the effects of tranquiliser type NPS are easy to predict; however, the duration of action and 
potency are less certain. Case series of deaths in Scotland between 2010-14 found 228 cases where phenazepam was detected in post mortem femoral blood samples. Phenazepam was the cause of death in two cases, and contributed to death in 54 cases (53).

CNS effects of the tranquiliser type NPS include sedation, ataxia, dysarthria, hypotonia, nystagmus, and coma. The immobility caused by CNS depression may result in rhabdomyolysis and hypothermia, and these should be considered in patients where tranquiliser type NPS use is suspected. As with conventional benzodiazepine overdoses, bradycardia and hypotension may also be predicted (47-50).

Treatment for intoxication with a tranquiliser type NPS is largely supportive. Hypotension should be corrected with IV fluids. Flumazenil may be considered; due to the variable potency and half-life of these agents, a flumazenil infusion may be necessary (47-50).

\section{Management for the Military Acute Care Practitioner}

Management of NPS consumption, in military personnel may be challenging for the Military Acute Care Practitioner, particularly when multiple substances are taken concurrently. Whilst their intoxication may be apparent, their diagnosis and the acute and chronic sequelae may be less obvious. NPS are often more potent than traditional illicit drugs (due to their full agonist action at receptors) (75-76), and routine laboratory screening may not be helpful in the acute phase. In this diagnostic "fog of war", an identification of the class of agent ingested may help the Military Acute Care Practitioner to treat the patient pro-actively (see Figure 1).

\section{Activated Charcoal and Intralipid}

The benefit of gastric decontamination in NPS misuse is uncertain. Trial of NPS is only advocated in patients who have taken NPS orally (in pill form), within an hour of presentation, who are not vomiting, and who are able to protect their own airway $(44,46-48,79)$.

The use of Intralipid (20\%) has been proposed to counteract the effects of lipid soluble molecules on the brain (78). There have been several case reports where patients have been resuscitated from mixed overdoses 
(psychotropic medications, antihypertensives, and a combination of both agents) following the administration of Intralipid. The agents taken in these cases included diazepam, temazepam, citalopram, quetiapine, sertraline, buproprion and lamotrigine (79-80. There is no evidence as yet that Intralipid is useful in the management of NPS toxicity, however, these cases indicate that Intralipid might be of benefit where high doses of benzodiazepines have been ingested. One review suggests that Intralipid may be of benefit where the patient has taken a lethal dose of cardiotoxic agents or sustained a cardiac arrest secondary to these drugs (80). However, administration of Intralipid should be weighed against potential side effects (allergic reactions, blood dyscrasias, deranged liver function, clotting disorders, hyperlipidaemia and pancreatitis (80).) Its use may interfere with laboratory assays and routine blood tests, which can impede treatment of the patient, particularly in the context of multiorgan failure (79).

\section{Discussion}

Current evidence suggests that the use of NPS amongst members of the civilian population is relatively low. However, research indicates two types of NPS, synthetic cannabinoids and synthetic cathinones, have become increasingly popular among US military personnel $(14,15,81)$, a comparable group to the UK Armed Forces. The available evidence would suggest the UK Armed Forces are a high risk group for NPS misuse, particularly the young male recruits, some of whom (approximately 1.34\%) would be classed as vulnerable adults (19).

For the small number of UK Armed Forces personnel who chose to misuse recreational drugs, NPS present a cheap, easily available alternative to "traditional" recreational drugs. They have the added benefit of being undetectable on current CDT batteries, and may be more potent than traditional drugs. We know that young, male Armed Forces recruits, particularly those within lower ranks, are at increased risk of misusing alcohol, illicit drugs and prescription medications. Self-reported drug seeking behaviour in comparable cohorts of young civilian men indicates that there is a strong link between traditional drug seeking behaviour and NPS misuse (1). Complex patterns of polysubstance use may increase the adverse side effects experienced by the user, including mortality, and present unique diagnostic challenges to military clinicians, with an unclear clinical picture of intoxication and toxicity (82). 
Little is known about the long-term harms produced by NPS; however many of the acute harms are incompatible with a career in the UK Armed Forces. It may be argued that NPS seeking behaviour in UK Armed Forces personnel is a maladaptive coping mechanism for meeting the demands placed on them by a military life and career. Alcohol is commonly misused within the UK Armed Forces community: between January 2012 and November 2016, 6,443 UK Armed Forces personnel were diagnosed with alcohol misuse or dependence (83). The penalties for alcohol misuse within the UK Armed Forces are not as immediately punitive as those for misusing recreational drugs, and there is a strong culture of rehabilitation, although it may be argued that this is due to the cultural acceptability of alcohol in the UK. Illicit drug misuse in UK Armed Forces personnel will almost always result in discharge.

All forms of substance use are higher among young male soldiers in the lower ranks who have recently been deployed (84-89); a group that is also at a higher risk of developing long-term mental health problems (e.g. depression, PTSD, suicidal ideation) (74, 890). As more soldiers now survive their injuries, increasing numbers of deployed military personnel are returning from combat with a range of comorbid physical and mental health issues that have complicated interrelationships with substance use and dependence. There is a high concurrence of problematic substance use with PTSD, depression, anxiety, traumatic brain injury, pain, survivor guilt and suicidal ideation $(86,88,91-97)$ all of which undermine the physical fitness and mental readiness of active military personnel and may actually contribute to harmful and criminal behaviours (98-99).

The misuse of NPS by military personnel is incompatible with the physical fitness and mental readiness needed for a successful career in the UK Armed Forces. This misuse has been associated with sequelae ranging from impaired memory, to critical illness, death and danger to others $(14,36,55,560,9100,101-103)$. Although there have been no reported cases where NPS misuse has impacted a soldier's performance in the battlefield, there are incidents recorded during training and on combat missions that illustrate the incompatibility of using NPS and active duty in the Armed Forces (14). We can surmise the detrimental effect of even one individual misusing NPS in a combat environment, where their ability to function in teams, mental readiness and physical capabilities may be impaired. During peacetime the effects of NPS misuse on an individual may negatively impact on the safety of others (e.g. drivers of heavy machinery or vehicles, handling live ammunition or explosives). Likewise, there is potential for harm to civilians; a pilot under the influence of NPS may maim or 
kill passengers and civilians on the ground. Finally, there is potential for damage to UK Armed Forces assets, such as aircraft, tanks, armoured vehicles and vessels, if personnel are operating under the influence of NPS.

The UK Armed Forces have a duty of care to protect personnel classed as vulnerable adults (those aged 16-18 and all personnel in Phase 1 training). This is particularly pertinent at a time when there is increasing pressure to increase the age of recruitment to over 18 (104). It may be argued that young, male Armed Forces personnel are particularly vulnerable to misusing NPS, and it is questionable whether dismissal from the Armed Forces is morally acceptable or whether rehabilitation should be the first course of action. It may be surmised that discharge from the UK Armed Forces for NPS Misuse dismisses the most damaged soldiers with more complex mental health needs, and that this may have negative implications for their function as civilians, and their future employment chances (8).

\section{Conclusion}

Novel psychoactive substances present a challenge to the military physician and to the UK Armed Forces. Currently, there are no routine screening tests for these substances. Military Acute Care Practitioners should be aware of the acute presentations of common types of NPS, and cogniscent of their potentially devastating physical and psychiatric sequelae. Early involvement of specialist secondary care teams may be needed. Prolonged supportive care may be necessary due to the potency of many of these agents.

Only a small number of military personnel have been identified as recreational drug users; however, whilst NPS remain undetectable, they may prove tempting to this small population. On their own, NPS may undermine both the health of soldiers and the capabilities of the UK Armed Forces. The misuse of NPS may be part of a larger issue of substance use and dependence among active military personnel, particularly young males. Whilst the misuse of "traditional" recreational drugs may be forgiven under exceptional circumstances, the dangerous and unpredictable sequelae of taking NPS make the practice, in general, incompatible with service life. 


\section{References}

1. Stephenson G and Richardson A. New Psychoactive Substances in England: A review of the Evidence. London: Crime and Policing Analysis Unit, Home Office Science; 2014

2. Ladler D, Drug Misuse: Findings from the 2014/15 Crime Survey for England and Wales (2nd Edition). London: Home Office; 2015.

3. Shapiro H. NPS Come of Age: A UK overview. 2016 URL: http://www.drugwise.org.uk/wpcontent/uploads/NPSComeofAge.pdf URL viewed: 21/7/16

4. Davies S, Wood D, Smith G et al. Purchasing 'legal highs' on the Internet-is there consistency in what you get? Q J Med 2010; 103:489-493

5. Shapiro H. Not for Human Consumption. An updated and amended status report on new psychoactive substances (NPS) and 'club drugs' in the UK. London: Drugscope: 45-46; 2015

6. Kamieński L. Shooting Up: A Short History of Drugs and War. Oxford: Oxford University Press; 2016.

7. Ministry of Defence. Freedom of Information request reference FOI2016/09506. URL: https://www.gov.uk/government/uploads/system/uploads/attachment data/file/600304/N umber of service personnel discharged for illegal drug possession.pdf URL viewed: 10 May 2017

8. Bird S, Compulsory Drugs Testing in the British Army: Assessing the data. RUSI. 2007. 152 (6): 54-59.

9. Ministry of Defence. JSP 835: Alcohol and Substance Misuse and Testing Version 2.0. 2013. URL: https://www.gov.uk/government/uploads/system/uploads/attachment data/file/425401/2 0131101-JSP 835-V2 0-U.pdf URL viewed: 21/7/16

10. Ministry of Defence. Army General Administrative Instruction 64, para 64.0422016

11. Savage M. Is the Army losing its war against drug abuse? Independent 15 March 2010 URL: http://www.independent.co.uk/news/uk/home-news/is-the-army-losing-its-waragainsgranet-drug-abuse-1921415.html URL viewed: 21/7/16

12. Gore SM, Bird AG, Ross AJ, Prison rights: mandatory drugs tests and performance indicators for prisons. BMJ. 1996. 312: 1411-3.

13. Brandt SD, Sumnall HR, Measham F, et al. Analyses of second-generation 'legal highs' in the UK: initial findings. Drug Test Anal. 2010. 2: 377-82.

14. Loeffler G, Hurst D, Penn A, et al. Spice, Bath Salts and the U.S. Military: The emergence of synthetic cannabinoid receptor agonists and cathinones in the U.S. Armed Forces. Military Medicine. 2012. 9: 1041-1048.

15. Vikhyat S, Bebarta MD, Ramirez S, et al. Spice: A new 'legal' herbal mixture abused by young active military personnel. Substance Abuse. 2011. 33: 191-194.

16. Johnson L A, Johnson R L \& Alfonzo C. Spice: A Legal Marijuana Equivalent. Mil Med 2011. 176 (6): 718-720

17. Johnson L A, Johnson RL, \& Portier R-B. Current "Legal Highs" J Emerg Med 2013: 40 (6);1108-1115

18. Brantley CL, Spice, Bath Salts, Salvia Divinorum, and Huffing: A judge advocate's guide to disposing of designer drug cases in the military. Army Lawyer. 2012. 16-37.

19. Ministry of Defence. UK armed forces biannual diversity statistics. URL: https://www.gov.uk/government/statistics/uk-armed-forces-biannual-diversity-statistics2016 URL viewed: 21/7/16

20. Hoyte C O, Jacob J, Monte A A, et al. A Characterization of Synthetic Cannabinoid Exposures reported to the National Poison Data System in 2010. Am J Emerg Med 2012. 60: 435-438 
21. Coppola M \& Mondola R. Synthetic Cathinones: Chemistry, pharmacology and toxicology of a new class of designer drugs marketed as "bath salts" or "plant food" Toxicol Lett 2012 211: 144-149

22. Bersani FS, Corazza O, Albano G et al. 25C-NBOMe: Preliminary Data on Pharmacology, Psychoactive Effects, and Toxicity of a New Potent and Dangerous Hallucinogenic Drug. . Biomed Res Int. 2014:734749. doi: 10.1155/2014/734749

23. Gee P., Schep L J, Jensen B P et al. Case series: toxicity from 25B-NBOMe - a cluster of Nbomb cases. Clin Toxicol 2015. 54(2):141-6

24. Wood D M, Looker J L, Shaikh I et al. Delayed Onset of Seizures and Toxicity Associated with Recreational Use of Bromo-dragonFLY. J Med Toxicol 2009. 5(4): 226-229

25. Coppola M and Mondola R. Bromo-DragonFly: Chemistry, Pharmacology and Toxicology of a Benzodifuran Derivative Producing LSD-Like Effects. J Addict Res Ther. 2012. 3(4): 1-3

26. Corazza O, Schifano F, Farre M et al. Designer Drugs on the Internet: a Phenomenon Out-ofControl? The Emergence of Hallucinogenic Drug Bromo-Dragonfly. Curr Clin Pharmacol. 2011. 6(2): 125-129

27. Hohmann N, Mikus G, Czock D. Effects and risks associated with novel psychoactive substances: mislabeling and sale as bath salts, spice, and research chemicals. Dtsch Arztebl Int 2014; 111(9): 139-47

28. Loi B, Corkery J M, Claridge $H$, et al. Deaths of individuals aged $16-24$ years in the UK after using mephedrone. Hum Psychopharmacol Clin Exp 2015. 30: 225-232

29. McClean JM, Anspikian A, Tsuang J W. Bath Salt Use: A Case Report and Review of the Literature. J Dual Diagn 2012. 8:3, 250-256

30. Zawilska J B. Methoxetamine - a novel recreational drug with potent hallucinogenic properties. Toxicol Lett. 2014. 402-407

31. Zanda M T, Fadda P, Chiamulera C et al. Methoxetamine, a novel psychoactive substance with serious adverse pharmacological effects: a review of case reports and preclinical findings. Behav Pharmacol. 2016. 27(6): 489-96

32. Toxbase. Etizolam. Toxbase App for Android. August 2014. Viewed 20 Dec 2016

33. Toxbase. Phenazepam. Toxbase App for Android. June 2014. Viewed 20 Dec 2016

34. Toxbase. 7-bromo-5-(2-fluorophenyl)-1,3-dihydro-2H-1,4-benzodiazepin-2-one. Toxbase App for Android. Sept 2015. Viewed 20 Dec 2016

35. Berry-Cabán C S, Kleinschmidt P E, Rao D S et al. Synthetic Cannabinoid and Cathinone Use Among US Soldiers. US Army Med Dep J. 2012. 19-25

36. Lapoint J, James LP, Moran CL, et al. Severe Toxicity Following Synthetic Cannabinoid Ingestion. 2011. Clin Toxicol (Phila). 49 (8): 760-764

37. Meijer KA, Russo RR, Adhvaryu DV, Smoking synthetic marijuana leads to self-mutilation requiring bilateral amputations. Orthopedics. 2014. 37 (4): e391-e394.

38. Hopkins CY \& Gilchrist, B L. A case of cannabinoid hyperemesis syndrome caused by synthetic cannabinoids. J Emerg Med 2013. 45 (4): 544-546

39. Young A C, Schwarz E, Medina G et al. Cardiotoxicity associated with synthetic cannabinoid, K9, with laboratory confirmation. Am J Emerg Med. 2012. 30: 1320.e5-1320.e7

40. Mir A, Obafemi A, Young A et al. Myocardial Infarction Associated With Use of the Synthetic Cannabinoid K2. Pediatrics. 2011. 128:1622-1627

41. Paul ABM, Simms L, Paul AE, et al. Not safe for consumption: Synthetic cannabinoids causing fatal acute rhabdomyolysis in two young men. Int J Case Rep Images 2016;7(7):431-435

42. Gershman J A \& Fass A D. Synthetic Cathinones ("Bath Salts") Legal and Health Care Challenges. P T. 2012 37(10): 571-572, 595.

43. Grane OM, Simmons J, Jacobson E et al. Alarming Trends in a Novel Class of Designer Drugs. J Clinic Toxicol. 2011. 1:108

44. Imbert L, Boucher A, Delhome G. Analytical Findings of an Acute Intoxication after Inhalation of Methoxetamine. J Anal Toxicol. 2014. 38: 410-415 
45. Gussow L. W-18, a synthetic opioid 100 times more potent than fentanyl. The Poison Review. 4 Feb 2016. URL: http://www.thepoisonreview.com/2016/02/04/w-18-a-syntheticopiate-100-times-more-potent-than-fentanyl/ URL viewed: 17 Nov 2016

46. Toxbase. 4-chloro-N-(1-[2-(4-nitrophenyl)ethyl]-piperidin-2-ylidene)benzenesulfonamide. Toxbase App for Android. Sept 2014. Viewed 17 Nov 2016

47. Talk to Frank. Drugs A-Z: Phenazepam. URL: http://www.talktofrank.com/drug/phenazepam URL viewed: 20 Dec 2016

48. Toxbase. Etizolam. Toxbase App for Android. August 2014. Viewed 20 Dec 2016

49. Toxbase. Phenazepam. Toxbase App for Android. June 2014. Viewed 20 Dec 2016

50. Toxbase. 7-bromo-5-(2-fluorophenyl)-1,3-dihydro-2H-1,4-benzodiazepin-2-one. Toxbase App for Android. Sept 2015. Viewed 20 Dec 2016

51. O'Connor L C., Torrence H J., McKeown, D A. ELISA Detection of Phenazepam, Etizolam, Pyrazolam, Flubromazepam, Diclazepam and Delorazepam in Blood Using Immunalysis ${ }^{\circledR}$ Benzodiazepine Kit. J Anal Toxicol. 2015 1-3

52. Lowe D. J., Ireland A., Torrance H et al. SODAS: Surveillance of Drugs of Abuse Study. Eur J Emerg Med. 2015. 15: 16

53. Shearer K, Bryce C, Parsons $\mathrm{M}$ et al "Phenazepam: A review of medico-legal deaths in South Scotland between 2010 and 2014." Forensic Sci Int. 2015. 254: 197-204.

54. Bush D M \& Woodwell D A. The CBHSQ Report. Update: Drug-Related Emergency Department Visits Involving Synthetic Cannabinoids. SAMHSA 2014. 1-8

55. Hurst D, Loeffler G \& McLay R. Psychosis Associated With synthetic Cannabinoid Agonists: A Case series. Am J Psych 2011. 168:10

56. Every-Palmer S, Warning: Legal Synthetic cannabinoid-receptor agonists such as JWH-018 May precipitate psychosis in vulnerable individuals. Addiction. 2010. 105 (10): 1859-60.

57. Ministry of Defence UK Armed Forces Mental Health: Annual Summary \& Trends Over Time, 2007/08 - 2014/15. 30 July 2017. URL:

https://www.gov.uk/government/uploads/system/uploads/attachment_data/file/451062/2 0150803_Annual_Report_14-15_Revised_O.pdf URL viewed: 10 Feb 2017.

58. Centers for Disease Control and Prevention. Acute Kidney Injury Associated with Synthetic Cannabinoid Use - Multiple States, 2012. MMWR 2013;62: 93-98

59. Castaneto MS, Gorelick DA, Desrosiers NA, et al. Synthetic Cannabinoids: Epidemiology, Pharmacodynamics and Clinical Implications. 2014. Drug and Alcohol Depend. 1: 12-41.

60. Trecki J, Gerona RR, Schwartz MD, Synthetic Cannabinoid - Related Illnesses and Death. 2015. N Eng J Med. 373: 103-107.

61. Every-Palmer S, Warning: Legal Synthetic cannabinoid-receptor agonists such as JWH-018 May precipitate psychosis in vulnerable individuals. Addiction. 2010. 105 (10): 1859-60.

62. Office of National Statistics. Deaths related to drug poisoning in England and Wales: 2015 Registrations. London: ONS 2016.

63. Kesha K, Boggs CL, Ripple MG, et al. Methylenedioxypyrovalerone ("Bath Salts"), Related Death: Case Report and Review of the Literature. J Forensic Sci. 2013, 58 (6): 1654-59.

64. Ross EA, Watson M, Golderberger B, 'Bath Salts': Intoxication. N Engl. J Med. 2011. 365 (10): 967-968.

65. Rosenbaum CD, Carreiro SP, Babu KM, Here Today, Gone Tomorrow...and Back Again? A Review of Herbal Marijuana Alternatives (K2, Spice), Synthetic Cathinones (Bath Salts), Kratom, Salvia divinorum, Methoxetamine, and Piperazines. J Med Toxicol. 2012.8 (1): 1532.

66. Airuehia E, Walker LY, Nitter J, A Review of "Bath Salts": Evolving Designer Drugs of Abuse. Journal of Child and Adolescent Substance Abuse. 2015. 24 (4): 186-190.

67. Toxbase. Amfetamines and similar stimulants - features and management. Toxbase App for Android. Jun 2013. Viewed 2 Jun 2017 
68. Sellors K., Jones A, Chan B. Death due to intravenous use of $\alpha$-pyrrolidinopentiophenone. MJA 2014 201(10): 601-603

69. Sykutera M, Cychowska M, Bloch-Boguslawska E. A fatal case of Pentedrone and $\alpha-$ Pyrrolidinovalerophenone Poisoning. J Anal Toxicol 2015. 39: 324-329

70. Ayres TC, Bond JW, A chemical analysis examining the pharmacology of novel psychoactive substances freely available over the internet and their impact on public (ill)health. Legal highs or illegal highs? BMJ Open. 2012.2 (4): 1-8.

71. Craig CL, Loeffler GJ, The Ketamine Analog Methoxetamine: A New Designer Drug to Threaten Military Readiness. Mil. Med. 2014. 179 (10): 1149-57.

72. Dawson P and Moffatt J D. Cardiovascular toxicity of novel psychoactive drugs: Lessons from the past. Prog Neuropsychopharmacol Biol Psychiatry. 2012. 39: 244-252

73. Cadogan, M \& Nickson, C. Life in the Fast Lane Blog (Internet). Australia: Mike Cadogan and Chris Nickson 2009 Nov - [cited 2 Jun 2017]. Available from: https://lifeinthefastlane.com/quiz-ecg-016-2/

74. Rolles S, 5 Reasons why the New 'Psychoactive Substances Bill' should be scrapped, and 1 Reason to commend it. 23 June 2015. URL: http://www.tdpf.org.uk/blog/5-reasonswhy-new-\%E2\%80\%98psychoactive-substances-bill\%E2\%80\%99-should-be-scrappedand-1-reason-commend-it URL viewed: 20/02/2017.

75. Castaneto MS, Wohlfarth A, Desrosiers NA, et al. Synthetic Cannabinoids pharmacokinetics and detection methods in biological matrices. Drug Metab Rev. 42 (2): 124-74.

76. Austin KG, Price LL, McGraw SM, et al. Longitudinal trends in use of dietary supplements by U.S. Army personnel differ from those of civilians. Appl Physiol Nutr Metab. 2016. 41 (12): 1217-1224.

77. Toxbase. Synthetic Cathinones. Toxbase App for Android. Jun 2014. Viewed 2 June 2017

78. Wong, GTC \& Irwin, MG. Poisoning with illicit substances: toxicology for the anaesthetist. Anaesthesia. 2013: 68(1); 117-124

79. Orr, K \& Bailey, R. The use of intralipid in the management of a mixed overdose. JICS. 2010. 1194): 268-269

80. Cave, G \& Harvey, M. Intravenous Lipid Emulsion as Antidote Beyond Local Anesthetic Toxicity: A Systematic Review. Acad Emerg Med. 2009. 16(9): 815-824

81. Vikhyat S, Bebarta MD, Ramirez $S$, et al. Complication of spice use in a deployed combat setting - seizure while on duty. Am J Addict. 21 (5): 496-497.

82. Institute of Medicine. Substance Use Disorders in the U.S. Armed Forces. Washington, DC: The National Academies Press.2013

83. Louise R, Hunter C, Zlotowitz S. The Recruitment of Children by the UK Armed Forces: A critique from Health Professionals. London: Medact.2016

84. Campise RL, Geller SK, Campise ME. Combat Stress. In Kennedy CH, Zillmer EA, eds. Military Psychology: Clinical and operational applications. New York: Guilford Press 2006: 215-240.

85. Shipherd JC, Stafford J, Tanner LR. Predicting alcohol and drug abuse in Persian Gulf War veterans: What role do PTSD symptoms play? Addictive Behaviors. 2005. 30 (3): 595-599.

86. Ames GM, Duke MR, Moore RS, et al. The impact of occupational culture on drinking behavior of young adults in the U.S. Navy. Journal of Mixed Methods Research. 2009.3 (2): 129-150.

87. Bray RM, Brown JM, Williams J. Trends in binge and heavy drinking, alcohol-related problems, and combat exposure in the U.S. military. Subst Use Misuse. 2013. 48 (10): 799810.

88. Larson MJ, Wooten NR, Adams RS, et al. Military Combat Deployments and Substance Use: Review and Future Directions. J Soc Work Pract Addict. 2012. 12 (1): 6-27.

89. Ministry of Defence Freedom of Information Request. 13 December 2016. URL: https://www.gov.uk/government/uploads/system/uploads/attachment_data/file/586418/F OI2016_10884.pdf URL viewed:09/03/2017 
90. Nicol M, Army drug scandal as 17 soldiers including two sergeant majors face boot after being caught using performance-enhancing chemicals. Daily Mail. 15 September 2013. URL: http://www.dailymail.co.uk/news/article-2420904/British-Army-drug-scandal-17-soldierscaught-using-performance-enhancing-chemicals.htmI URL viewed: 10 Feb 2017

91. Shipherd JC, Stafford J, Tanner LR. Predicting alcohol and drug abuse in Persian Gulf War veterans: What role do PTSD symptoms play? Addictive Behaviors. 2005. 30 (3): 595-599

92. Shen YC, Arkes J, Williams TV. Effects of Iraq/Afghanistan Deployments on Major Depression and Substance Use Disorder: Analysis of Active Duty Personnel in the US Military. American Journal of Public Health. 2012. 102 (S1): S80-S87.

93. Larson MJ, Adams RS, Mohr BA, et al. Rationale and Methods of the Substance Use and Psychological Injury Combat Study (SUPIC): A Longitudinal Study of Army Service Members Returning from Deployment in FY2008-2011. Subst Use Misuse. 2013. 48 (10): 863-879

94. Adams RS, Larson MJ, Corrigan J, et al. Frequent binge drinking after combat-acquired traumatic brain injury among active duty military personnel with a past year combat deployment. Journal of Head Trauma and Rehabilitation. 2012. 27 (5): 349-360.

95. Seal KH, Cohen G, Waldrop A, et al. Substance use disorders in Iraq and Afghanistan veterans in VA healthcare, 2001-2010: Implications for screening, diagnosis and treatment. Drug and Alcohol Dependence. 2011. 116 (1-3): 93-101.

96. Nazarian D, Kimerling R, Frayne SM. Posttraumatic stress disorder, substance use disorders, and medical comorbidity among returning U.S. veterans. Journal of Traumatic Stress. 2012. 25 (2): 220-225.

97. Macmanus D, Dean K, Jones M, et al. Violent offending by UK military personnel deployed to Iraq and Afghanistan: a data linkage cohort study. Lancet. 2013. 381 (9870): 907-17

98. Rosellini AJ, Monahan J, Street AE, et al. Using administrative data to identify U.S. Army soldiers at high-risk of perpetrating minor violent crimes. J Psychiatr Res. 2017. 84: 128-136

99. Motbey CP, Karanges E, Li KM, et al. Mephedrone in adolescent rats: residual memory impairment and acute but not lasting 5-HT depletion. PloS one. 2012. 7: e45473.

100. Schifano F, Corkery C, Ghodse AH. Background: suspected and confirmed fatalities associated with mephedrone (4-methylmethcathinone, 'meow meow') in the United Kingdom. J Clin Psychopharmacol. 2012. 32 (5): 710-4.

101. Freeman TP, Morgan CJ, Vaughn-Jones J, et al. Cognitive and subjective effects of mephedrone and factors influencing use of a 'new legal high'. Addiction. 2012. 107: 792800.

102. Gibbons S, Legal Highs-Novel and Emerging Psychoactive Drugs: A chemical overview for the toxicologists. Clin Toxicol. 2012. 50: 15-24.

103. Bray RM, Brown JM, Williams J. Trends in Binge and Heavy Drinking, Alcohol-Related Problems, and Combat Exposure in the U.S. Military. Subst Use Misuse. 2013. 48 (10): 799810.

104. Dabbs C, Watkins EJ, Fink DS, et al. Opiate-related dependence/abuse and PTSD exposure among the active-component U.S. military, 2001 to 2008. Mil Med. 2014. 179 (8): 885-90. 
Legends

Figure 1: Figure illustrating an approach to the assessment and management of a service person who has taken Novel Psychoactive Substances

Figure 2: Figure illustrating prolonged QTc and widening of the QRS complex in a patient who overdosed on amitryptaline. Similar cardiotoxicity may be observed following ingestion of opioid type novel psychoactive substances. Reproduced with permission from www.lifeinthefastlane.com (72) 
Service Person

identified as intoxicated

(if unresponsive/ low GCS, call 999)

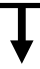

Approach patient if safe to do so

Ensure they are disarmed

(involving Military Police if necessary)

ull History (+/- collateral history)

NPS taken (if possible retain sample for testing)

Time and manner of administration

Note if dose was staggered

Other agents taken concurrently e.g. alcohol

Patient's pre-existing medical conditions (if any),

current medications and allergies

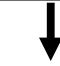

\section{Full Examination}

CVS - Note tachy/bradycardia, dysrhythmia,

murmurs. Measure serial blood pressures

RS - Respiratory rate, oxygen levels, added sounds on auscultation

CNS - Note pupil size and reactivity, reflexes, tone, and gait

GS - Vomiting, abdominal discomfort

Skin - Note any Injection sites, Necrosis, Rash

Other - Conjunctival injection

Serial temperature measurements

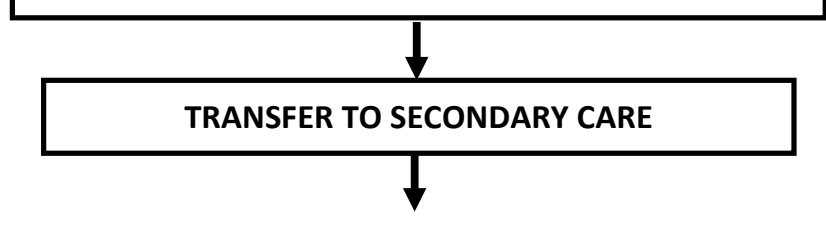

Consider activated charcoal if

- Oral agent

- Within $1 \mathrm{hr}$ of ingestion

- $\quad$ Airway is protected

- Patient is not vomiting

Adult dose 50g (45, 47-49)

\section{Further Management}

Oxygen therapy as needed

Continuous cardiac monitoring (min $12 \mathrm{hrs}$ for most patients)

Bloods: Full blood count, Urea and Electrolytes, Bone profile, Liver Function Tests, C-Reactive Protein, Lactate,

Glucose

Blood and urine samples for toxicology

Arterial or Venous blood gas

EARLY SPECIALIST/CRITICAL CARE REVIEW FOR ORGAN/MULTIORGAN FAILURE

Supportive treatment (agent dependent) 